\title{
A retrospective study of fracture cases managed in the veterinary teaching hospital; 181 cases $(2014-2018)$
}

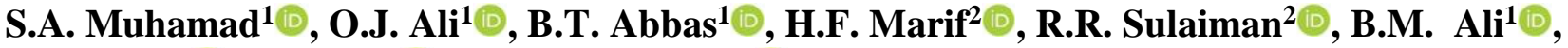 \\ D.A. Raza' ${ }^{1}$, H.H. Ali ${ }^{2}$ and G.M. Ahmad ${ }^{1}$
}

${ }^{1}$ Department of Surgery and Theriogenology, ${ }^{2}$ Department of Internal Medicine, College of Veterinary Medicine, University of Sulaimani, Sulaimani, Iraq

Article information

\section{Article history:}

Received October 27, 2019

Accepted January 6, 2020

Available online September 9, 2020

\section{Keywords:}

Bone

Dog

Cat

Birds

Fracture

\begin{tabular}{l}
\hline Correspondence: \\
O.J. Ali \\
othman.ali@univsul.edu.iq
\end{tabular}

\begin{abstract}
The aim of the study to evaluate 181 cases of different types of fractures in age and sex of the different breeds that were admitted to the Veterinary Teaching Hospital of College of Veterinary Medicine, University of Sulaimani, over the years 2014 -2018. From a total of 734 clinical cases, 181 were diagnosed as fractures. From cases, dogs represented 49.72\% (90/181), whereas cats represent $18.23 \%$ (33/181) and birds represented 22.09\% (40/181). The etiology of the fractures multifactorial, but car accidents represented the main cause of fractures particularly in dogs. Femoral fractures were reported as the most prevalent types of fractures that represented $26.51 \%$ (48/181), followed by fractures in radius-ulna $19.33 \%$ $(35 / 181)$, tibia-fibula $13.81 \%(25 / 181)$ and the pelvis $9.94 \%(18 / 181)$. All the cases were diagnosed on the bases of case history, clinical signs, physical examination and finally confirmed by using digital X-ray which offered an excellent scope and contrast than the traditional method. From a total of 181 cases, 6 cases were found hopeless, 45 cases underwent surgical internal fixation and the remaining 130 cases were fixed by external coaptation. Internal fixations were found to be very convenient and without any difficulties, on the contrary to the cases with external cooptation were not. We recorded postoperative inflammation in 4 cases, as well as mal-union was recorded in 5 cases and incomplete alignment in 2 cases was found. We concluded that fractures in pet animals are common in Sulaimani province, which must be considered, and the best-employed methods of fracture repair were the internal fixation techniques, particularly intramedullary pinning.
\end{abstract}

DOI:, (C2020, College of Veterinary Medicine, University of Mosul.

This is an open access article under the CC BY 4.0 license (1http://creativecommons.org/licenses/by/4.0/).

\section{Introduction}

Pets animals susceptible to many accidental disorders especially orthopedic disorders. During the last decades, pets care has been progressed dramatically in our world population, and bone fractures represent the most common major problem particularly in dogs (1).

Fracture is generally causing a varying degree of soft tissue damages such as bruised muscle, torn vessels and damaged periosteum. It often occurs in pet animals due to a trauma, such as jumping from a height or being hit by a vehicle. The severity of the fracture is dependent on the etiology, anatomical locations and age of the animal, which may be hairline, multiple-pieces or compound fractures $(2,3)$. The incidence and percentage could be varied among different animal species, different regions and countries, for instances, in a large veterinary hospital in North America for evaluation of injuries it was recorded that from approximately $35 \%$ of dogs and cats were examined, the overall mortality rate was $9 \%$ (4).

In a retrospective study in Tripoli-Libya (2005 to 2010), from a total of 650 clinical cases 116 cases were diagnosed 
as fractures. From these total $116(17.8 \%)$ cases, dogs constituted $67 \%$ while cats $23 \%$. Moreover, the femur was the most inflicted fractured bone in cats and dogs were representing $25 \%$ and $37.5 \%$ respectively (5). Similarly, in a survey at the Faculty of Veterinary Medicine at the University of Cairo, from October 2010 to April 2013 it was recorded that the pelvic limbs accounted a greater percentage of fracture in dogs $(50.60 \%)$ and cats $(69.39 \%)$. Interestingly, most of the fractures were involved in the midshaft of the femur, which were accounted for $(46.10 \%)$ in dogs (6). It was also confirmed by other studies, that fractures of the femur is common in pet animals (dog and cat), were accounting for $20-25 \%(7,8)$.

Fractures are diagnosed by radiographical imaging using two-view technique. If the surgeon doubt about anatomical structures, the opposite could be radiographed for the proper comparison (9). The specific signs of fracture on radiographic film include a break in the bone, where a line of radiolucency appear when fragments are distracted, however, a line of radio-opacity appears when fragments are overlapped or compressed (10). Currently, fractures are treated by using a variety of surgical and nonsurgical interventions. Different options, ranging from external to internal fixation, cage resting and amputation as a final choice could be considered. The Selection of the appropriate methods of fixation is depending on types of fracture, severity of fracture, facilities and the owner's agreements (11-13).

The aim of this study is to show the incidence of fractures in pet animals, were presented into the veterinary teaching hospital, College of veterinary medicine, University of Sulaimani, Iraq, from 2014 to 2018 and how they were properly fixed with different methods.

\section{Materials and methods}

\section{Animals}

This study was conducted from 2014 to 2018 in all cases was admitted into the veterinary teaching hospital belonging to the college of veterinary medicine, University of Sulaimani. During this period, out of 734 clinical cases, 181 cases were diagnosed as fractures (Table 1 and 2). Clinical assessment of lameness was evaluated by observation for weight-bearing, swelling and pain during palpation of the fractured limbs.

\section{Anesthetic technique}

Anesthesia was made by subcutaneous injection of atropine Sulphate, a premedicated drug, at a dose of 0.04 $\mathrm{mg} / \mathrm{kg}$. Twenty -to- thirty minutes later, was followed by intramuscular injection of a mixture of Xylazine $2 \%$ and Ketamine $10 \%$, at a dose of $1 \mathrm{mg} / \mathrm{kg}$ and $15 \mathrm{mg} / \mathrm{kg}$ as one bolus injection (14).
Table 1: Show the number of fractures in different animal species

\begin{tabular}{lc}
\hline Animal species & Number of animals \\
\hline Dog & 90 \\
Cat & 33 \\
Bird & 40 \\
Rodent & 8 \\
Deer & 3 \\
Calf & 3 \\
Sheep and goat & 4 \\
\hline Total & 181 \\
\hline
\end{tabular}

Table 2: Show the number of fractures in different anatomical locations

\begin{tabular}{lc}
\hline Position of fracture & Number of animals \\
\hline Pelvic & 18 \\
Femur & 48 \\
Tibia and fibula & 25 \\
Knee & 6 \\
Metatarsal & 2 \\
Digit & 16 \\
Humerus & 11 \\
Radius and ulna & 35 \\
Elbow & 14 \\
Carpal joint & 3 \\
Metacarpal & 3 \\
\hline Total & 181 \\
\hline
\end{tabular}

\section{Radiologic examination}

In this retrospective study a precise digital $\mathrm{x}$-ray machine supplied with a digital detector of a thin-film transistor (TFT) was used to take an x-ray for the fractured bones (Veterinary Portable digital and captured radiographic system machine versa view W (800) 346-9729). Using of digital radiographic practice through transmitting the image from the screen film to the digital radiographic panel is not simple; the radiologist must be familiar with a new skill in changing in the workflow process. Software Metron always starts in the "Database Browser", which is a control panel for taking X-ray images. The basic conformation of the Metron database includes owner names, animal detail and the date of radiography.

\section{Management of fractured bones}

Generally, the fractured bones were grouped into two main groups; the first group includes those cases with fractured that could not be managed by surgical intervention and the fractured segments were immobilized by external cooptation such using plaster cast of Plaster of Paris or fiberglass's. The second group includes those fractures that were fixed by an intramedullary pin, cerclage wire or bone plate and screw. 


\section{Surgical preparation}

In the second group, the surgical areas were prepared for aseptic operation. The hair clipped, shaved and the skin scrubbed with water and soap. The area is then disinfected by an antiseptic and swabbed by povidine-iodine $10 \%$ and draped by the surgical drapes. A longitudinal skin incision was done extending the proximal to the distal level of the fractured fragments. The subcutaneous tissues with the fascia were incised. Then by blunt dissection between the muscular fibers the fracture area was approached. The splintered fragments were reduced, aligned and appropriate methods were selected for fixation. Intramedullary fixation of the pin (k-wire) was accomplished by fixing the intramedullary pin into the pin chuck introducer, then the pin was introduced into the medullary cavity of the proximal fragment was driven proximally and rotated through cancellous bone until it is point emerges through the proximal portion far from the joint such as through the intertrochanteric fossa of the femur. The pin chuck introducer was then fitted to the proximal end of the intramedullary pin. With careful rotatory motion, the intramedullary pin was withdrawn until the distal end of the pin flush with the fracture. After the reduction and alignment of the proximal and distal fragments accomplished, the pin was driven down the medullary cavity of the distal fragment. A pin cutter leaving little portion above the skin cut off the protruding portion of the pin and then the skin was sutured with non-absorbable silk or nylon surgical threads (Figure 1). Bone plates and screws were also used for cases that were not comfortable for intramedullary pining such as radial fracture. The plates were chosen according to the diameter and length of the bones. Bone plates were applied to the fractured fragments, then drilling through the plate holes down to the bone cortex, where the screws fixed by a screwdriver. Additionally, selected cases such as oblique fracture or fracture of the flat bones a cerclage wire were used. Suturing the separated muscle into their normal anatomical position, the fascia and subcutaneous tissues are sutured by simple interrupted suture with 3.0 Vicryl. Finally, the skin was sutured with silk size 0 . Immediate postoperative radiographic (Medio-Lateral views) examination was performed for all animals in order to evaluate the quality of fracture reduction, fragment apposition and fragment alignment.

\section{Post-operative care}

Antibiotic and analgesic medicines were injected in order to prevent post-operative pain and infection complication. The animal owners were advised to take an x-ray after 2, 4 and 6 weeks in all instances. The intramedullary pins were left in place for about 6 weeks and finally withdrawn by using introducer with pin chuck, however, the cerclage wire, bone plate, and screw were not removed.

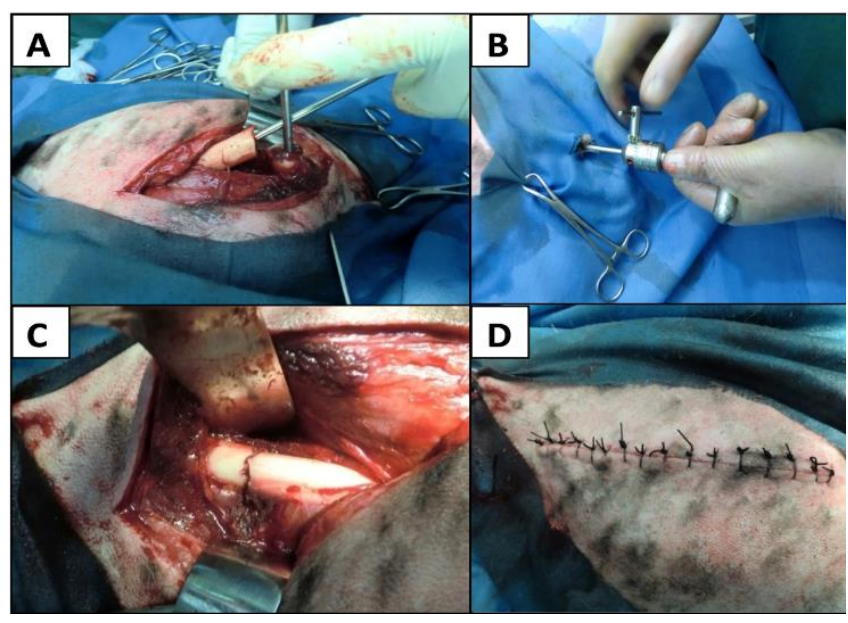

Figure 1: Steps of fracture fixation in dogs; the pin was introduced into the proximal fragment (A), the pin chuck introducer was then fitted to the proximal end of the intramedullary pin in order to driven into the distal fragment (B), which completely fix the fractured segments (C) then the muscle, fascia and the skin were sutured (D).

\section{Results}

In this study, we found that the incidences of fractures in companion pet animals in Sulaimani province constitute a large number of clinical cases. Therefore, these fractured cases should be considered in order to accomplish all the requirement of orthopedic instrumentation for proper immobilization of the fractured bones. These greater facilities such as x-ray imaging and surgical instrumentation will aid in the proper and rapid treatment of such clinical cases as they presented in various forms of fractures annually. The percentage of fractures from 2014 to 2018 it was about $24.65 \%$ (181/734) out of the other clinical cases that were admitted to our veterinary teaching hospital (Figure 2). These cases were from different regions of Sulaimani province, although cases were also admitted from places out of Sulaimani province.

During this period, it was observed that the percentage of fractures were not constant annually, they were $6.12 \%$, $40.57 \%, 85.36 \%, 48.43 \%$ and $35.35 \%$ in $2014,2015,2016$, 2017 and 2018, respectively (Figure 3). Intestinally, the percentage of these fractured cases were reported the highest incidence during 2016 (85.36\%). Moreover, the affected animals were regularly examined post-operatively through clinical examination of the animals including weekly observation of the physical activity such as movement, weight bearing and evaluation the degree of pain of the broken legs. 


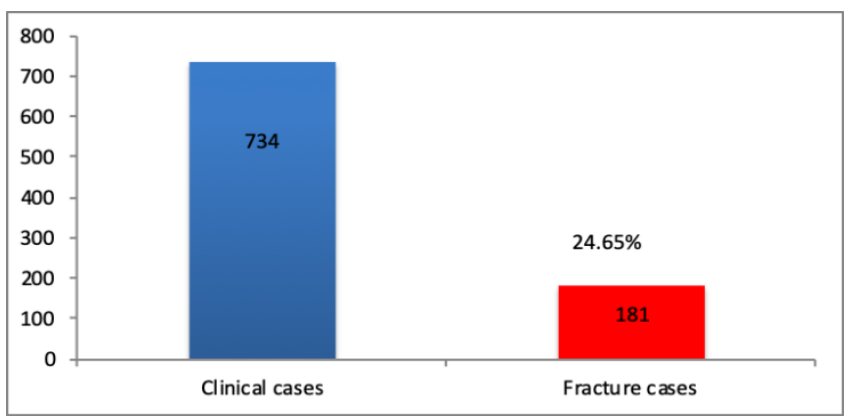

Figure 2: the numbers of fracture cases from 2014 - 2018 out of the total clinical cases were treated in the veterinary teaching hospital/ college of Veterinary Medicine/ University of Sulaimani.

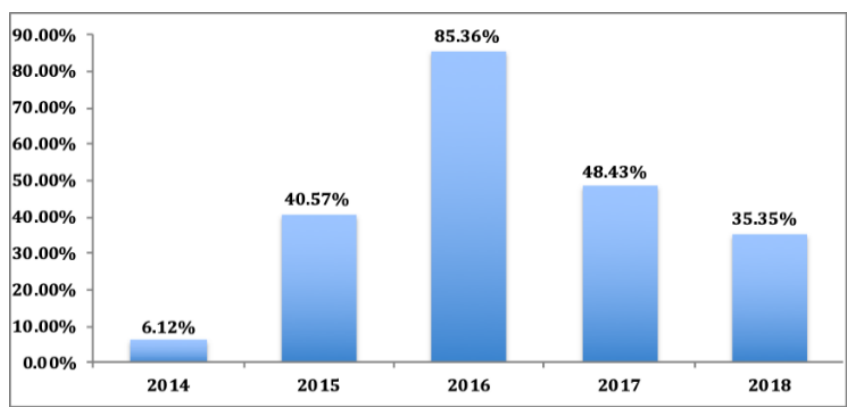

Figure 3: the percentages of fractures of pet animals from 2014 to 2018 were reported in the veterinary teaching Hospital/ College of veterinary medicine/ University of Sulaimani.

The majority of fractures were occurred in dogs, cats and birds. Dogs represented 49.72\% (90/ 181 cases), whereas cat represented $18.23 \%$ (33/181 cases) and birds represent 22.09 $\%$ (40/ 181) that was the second highest animals with fractures among all the clinical cases. Dogs from different breeds were admitted for orthopedic reasons, but the admitted cats were almost from a local breed (Figure 4).

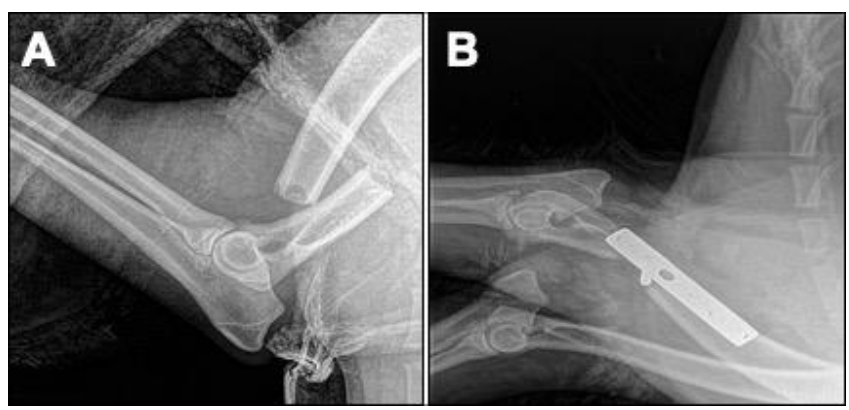

Figure 4: Radiographic image of a dog with a complete transverse fracture of the humeral shaft (A), that has been fixed by bone plate and screws (B).
Although, different species of birds were admitted for radiological examination, including chicken, roaster, eagles, parrots, pigeon, and quail (Table 1) (Figure 5). Those birds were exposed to various form of accident such as hitting by an object, entrapment, and gunshots.
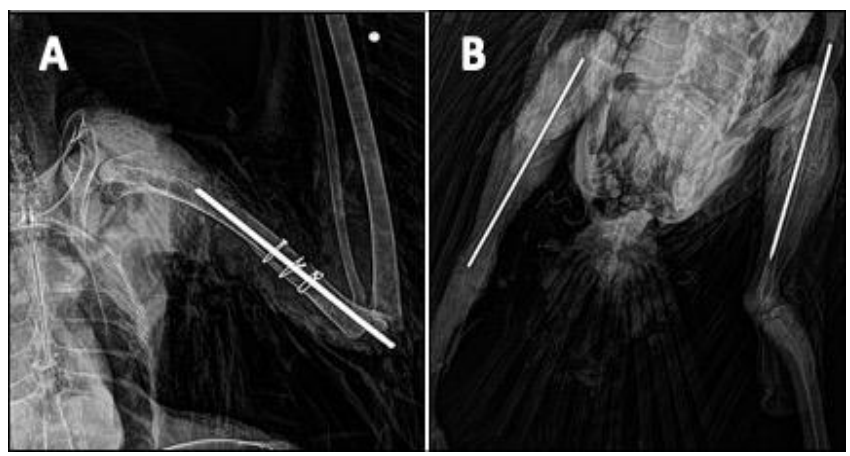

Figure 5: Multiple fractures in a bird involving the left wing (A) and both legs (B). Intramedullary pins were used to fix the fractured bones and the cerclage wires (A) were applied on the fractured humorous to re-enforce the bone fixation.

The etiologies of fractures were different causes of different animals' species and the different bones of the appendicular system (Table 1). It has been documented that major causes of fractures were car accident, particularly in the dogs. Moreover, it was revealed that femoral fracture was the most common types of fracture, which was represented $26.51 \%$ (48 /181) from all the clinical cases. The other most commonly encountered types of fractures were radius-ulna, tibia-fibula and the pelvis, which were $19.33 \%$ (35/ 181), $13.81(25 / 181)$ and $9.94 \%$ (18/181) respectively.

During orthopedic practice, from the total of 181 cases, 6 cases were found hopeless due to multiple and complete dissolution of the bones such as pelvic and vertebral fractures (Figure 6).
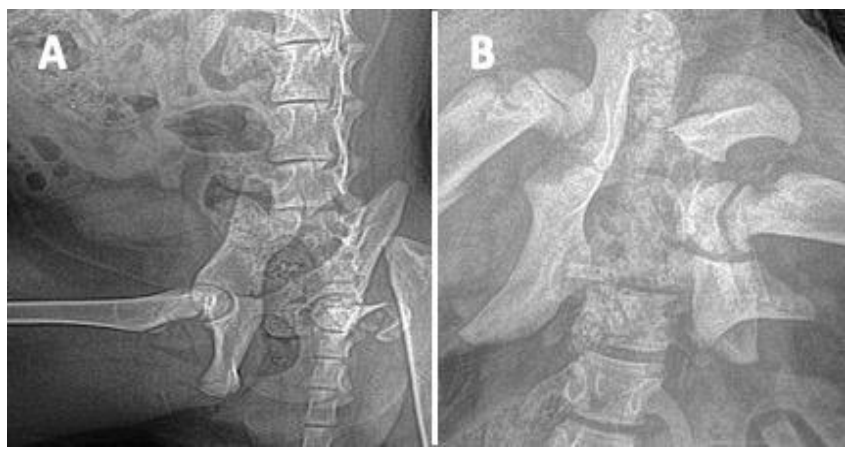

Figure 6: Radiographic images of pelvic and femurs, showing complete dissolution of the pelvic bones and femurs in cat $(\mathrm{A})$ and $\operatorname{dog}(\mathrm{B})$. 
Totally, 45 cases underwent surgical intervention by using intramedullary pins (39 cases), cerclage wire ( 2 cases), and bone plate and screws ( 4 cases). The other remaining 130 cases were treated by simple external coaptation using both fiberglass and the Plaster of Paris (Gybsona) for fixation of the fractured segments (Figure 7). Mostly, the results were good, except for few cases were suffered from post-operative inflammation (4 cases), mal-union (5 cases) and incomplete alignment or deformities ( 2 cases). Hopeless cases include those cases with pelvic fractures that were accompanied by internal visceral damages.

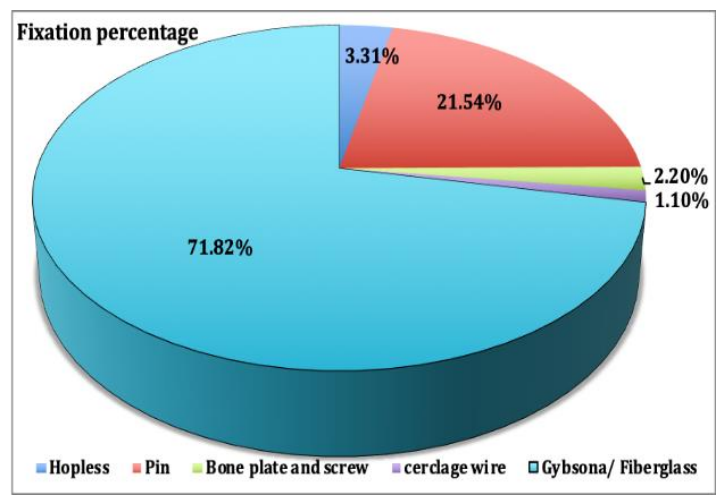

Figure 7: Show the percentage of fracture fixation methods from 2014 to 2018 in the veterinary teaching Hospital, College of veterinary medicine/ University of Sulaimani.

On post-operative physical examination for those cases were fixed with intramedullary pins, they showed marked soft swelling at the fractured site mostly up to the first week of operation. The feeding, drinking and body temperature were normal while on their gaits they were still lame. During the first week of post-operation the animals were irrespective to move their operated limbs as a result of severe tissue trauma either due to preoperative injury or trauma during surgery. The post-operative clinical evaluation of the fractured limbs includes mobility of the animals on their functional limbs from the third post-operative weeks. The early mobilization of the affected limb in the dogs and cats also suggestive of quality of healing in some order as weight bearing on the fractured limb was considered as an indicative parameter for the assessment of the quality bone healing.

The results for the post-operative radiographic images for cases that fixed by intramedullary pins have exhibited the formation of excess external callus from the second postoperative week. They appeared as a small bridge between the two fragments, but the amount of callus was minimal comparable with traditional fracture, and no soft tissue swelling on radiographic images were observed with no possibility of pin dislocation or migrating out from the medullary cavity. The radio-density of the callus around the fractured bones was uniform when compared to that of the cortical bones, which suggesting maturation and the remodeling stages of fracture healing. Moreover, the fractured bone fragments were found accurately aligned without any remarkable deformity, which provides very good gripping when fixed with an intramedullary pin that might be attributed to the reasons for good appositional alignment of the fractured segments (Figure $8 \mathrm{~A}$ ). However, other cases that were fixed by means of bone plate and screw, on the post-operative radiographic finding, showed signs of more tissue damages and formation of a large amount of soft and hard callus (Figure $8 \mathrm{~B}$ ).

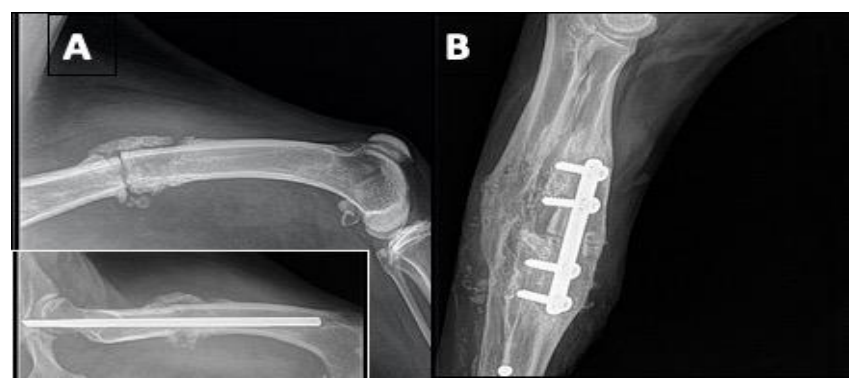

Figure 8: Radiographic images of the fractured bones in dogs, showing the callus formation at the fracture site after 6 weeks of their fixation by intramedullary pin (A) and bone plate and screw (B).

In the cases of external cooptation using both fiberglass and Plaster of Paris) (Gypsona), it was found that the external callus also formed from the second week of coaptation. The callus appeared as a bridge between the two fragments, but their amount was higher comparable with traditional fracture that fixed by internal fixation and radiographic signs of soft tissue swelling were found. However, the fractured fragments were found not perfectly aligned when compared to the internal fixation methods (Figure 9).

Conclusively, different species of animals (dog, cat, bird, rodent, and small ruminants) were referred to our veterinary Teaching Hospital for routine radiography. After physical examination the patient underwent digital radiography of different positions under sedation or general anesthesia. For this reason, it is fundamental for the orthopedic study to have a high-quality digital x-ray in order to make an accurate diagnosis. Moreover, digital technology is making the process of diagnosis much faster than traditional radiography. The radiographic software allows to adjust brightness, contrast and to zoom images on a single exposure. Techniques are simplified; the radiographic machine is built-in into the software, which contains all the parameters for different species of animals with optional different location of the body. These properties assist the technician on how to prepare the animals for radiography and to what extend the radiograph should look like when the 
animal is positioned properly and using appropriate radiographic procedure.
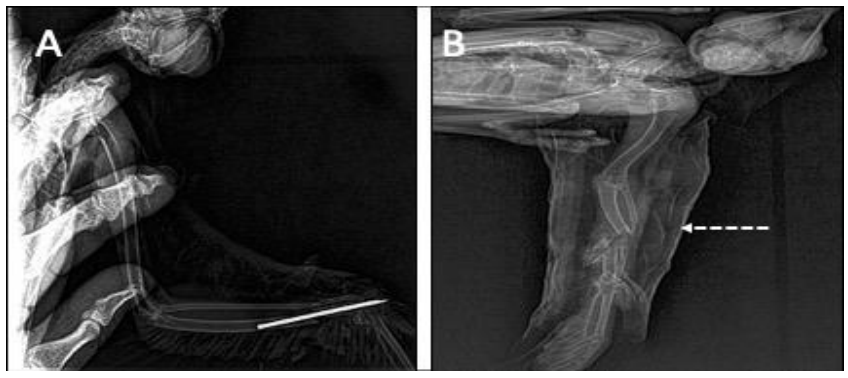

Figure 9: Post-operative radiographic images of radius and ulna in pigeons were fixed with intramedullary pin (A) and Gybsona (B). Bones fragments were less accurately aligned when fixed by external coaptation than the pins.

\section{Discussion}

Bones of the skeletal system provide supporting tools for the whole body, assist in angular movement and locomotion by acting as a lever within the muscles. Moreover, skeletal bones protect visceral organs from trauma (15). Moreover, bones perform minerals homeostasis and acid-base balance and maintain the hematopoietic environment within the marrow spaces (16). Thus, when this system exposed to a disease or trauma such as fracture, it will affect on the abovementioned vital functions. Additionally, the surrounding tissues also involved and traumatized, which may complicate the situation $(17,18)$. The etiologies of fractures are multifactorial although traffic accidents were listed as the line of causes. The other inflicted causes could be indoor trauma such as falling from a height place, biting and hitting by an object or companion people $(19,20)$. Diagnosis of fractures depends on the history, clinical signs, physical examination and final confirmation by using digital imaging. Digital imaging is new from that describe general radiography when the radiographic images transformed from a traditional form to a digital form and are capable of being displayed on a digital monitor $(21,22)$. During this study, digital radiography offered an excellent tool for diagnosis of fractures, where two planes imaging were taken in order to confirm and realized the pattern of fracture. Recently, this machine has become available in the markets, economically feasible and technically provides an excellent technology that could replace the traditional screen-film technology (23, 24). Although, using such machine and transition from a traditional screen-film to digital imaging technology is not simple, it require training a new skills, change in the workflow process and retraining at times of radiography $(9$, 25). Digital technology provides faster methods than the traditional radiography, and the inbuilt software allows adjustment of contrast, brightness, and storing these files in a specific folder under the names of the owners with their animals' details and date of exposure. As long as, the patient when positioned correctly, particularly focusing the x-ray tube toward the proposed anatomical region according to the digital protocol and using an accurate exposure protocol it will make the radiologist to take an accurate image with a high contrast level $(26,27)$.

Up-to-date, this retrospective data is the first documentation of fractures in the department of surgery at the veterinary teaching hospital on the basis of using digital $\mathrm{X}$-ray machine for diagnostic purposes. During this period (2014-2018) a large number of pet animals were admitted for different clinical reasons. From these clinical cases a considerable number were diagnosed for fractures. Dogs were formed the highest number of fractured cases were representing $49.72 \%$ (90/ 181 cases). Similarly, it has been documented by different studied that dogs and cats are the major clinical cases, where the femurs are more prone to fractures $(5,6,28)$. For instances, in a retrospective study from 2005 to 2010 in Libya, were undertaken to record the incidence and pattern of fractures in dogs and cats, it was recorded that dogs represented $67 \%$ from a total of 650 cases, where the femoral bones among the highest fractured bones $(37.5 \%)(5)$. In a study it was recorded that the diaphyseal fractures formed one quarter of all fractures of long bones (29). Similarly, the present study recorded that the femur was among the highest fractured bones, which representing $26.51 \%$ (48 /181), where, diaphyseal fracture was the most common types of fractures. Although, in another study, it has been recorded that most of the diaphyseal fracture was located at the distal $(54.55 \%)$ part, followed by mid shaft $(27.27 \%)$ and then the proximal part $(18.18 \%)$ of the long bones (30). These data indicate that fractures in pet animals could be a significant issue the veterinary surgeons in Sulaimani province, which require greater facilities in order to properly diagnose and treat different types of fracture. The owners were advised to pay attention to their animals about the predisposing factors of fractures in order to reduce the possibility of fracture.

Fracture consolidation is a fundamental biological process of bone repair in human and animal models. Many methods have been suggested to enhance bone healing and decrease the time of fracture union (31-33). Open reduction and proper stabilization of fractured bones with using intramedullary fixation pin is easy in application, inexpensive and the basic principles of repair are followed. However, post-operative complications could be an expected outcome of fracture repair, although, surgeons can reduce the incidence of these post-operative complications by selecting an appropriate surgical method (34-36). The important factors in repairing of fracture include using appropriate surgical method, selection of the suitable diameter/size pins or bone plate and screw, preservation of soft tissues form injury and an adequate post-operative care (35). Internal 
fixation using either intramedullary pins (IMP) or bone plate and screw (Figure $8 \mathrm{~B}$ ) for the dogs and cats were found very convenient, applicable and without much difficulty, due to of some biomechanical properties like its non-corrosive, not absorbed, not degraded within the skeletal system and immunologically is inert. Similarly, fractures in the rodent species such as squirrel, rabbit, and guinea pig were also fixed by using an intramedullary fixation. Nevertheless, other internal fixation methods may be used such as bones plate and screw, were eligible but it was more time consuming with greater post-operative tissue reactions (37). External coaptations were easier for application but incomplete alignment and more callus formation were observed (38). On post-operative physical examination, the internally fixed fractured bones showed signs of soft tissue swelling, mostly up to the first week of operation, but the animals were still lame, while, feeding, drinking and body temperature were normal. This post-operative sign, irrespective of the animal species was due either to the preoperative trauma by the bone fragments and the manipulative soft tissue injury during surgery $(18,39)$. The clinical evaluation of the operated functional limb usage showed a remarkable progress from the third post-operative week. The early post-operative ambulation of the fractured limbs in dogs treated with intramedullary pin was also suggestive of an excellent quality of bone healing in a some order such as weight bearing which is considered to be one of the most important gross observable parameter for assessing the quality of bone healing $(40,41)$.

Radiographically, fractured cases were fixed by intramedullary pins were showed perfectly aligned bone contours without any remarkable distortion of the bone fragments. Thus, the bone fragments were had a good gripping when fixed properly and this were attributed to the reasons of proper retention and alignment of the proximal and the distal fractured fragments, which was responsible for proper callus formation. Thus, the quality and the quantity of callus formation around the fractured bones definitely depends on methods and accuracy of fracture fixation; sufficient rigidity and stability of fixation of the bone fragments leads to the formation of the minimum amount of callus (42). Additionally, proper post-operative physical therapy and daily exercises to rehabilitate the patient's locomotion are an important aspect that must be considered by the owners (18). Recently, different materials are used in order to enhance healing process of the fractured fragments such as application of bone grafts, stem cell therapy, platelet rich plasma, and chemical bisphosphonate compound (43$45)$.

\section{Conclusion}

On the basis of these collected data in this retrospective study in Sulaimani province, it was concluded that the most common technique for internal fixation was the intramedullary pining in long bones, which followed by bone plate and screw and cerclage wiring. Although, application of cast bandages such as Gybsona and fiberglass were more eligible for application, but they were not free from malalignment.

\section{Acknowledgment}

The authors would like to thank the department of surgery and the veterinary teaching hospital of the college of veterinary medicine, university of Sulaimani for their support and preparation of data and the radiographic images.

\section{Conflict of interest}

The authors declare that this paper it does not have conflict of interest.

\section{References}

1. McCartney W, Garvan CB, Kiss K. Repair of thirty-six fractures in dogs using the Mennen clamp-on plate: preliminary results. Vet Comp Orthop Traumatol. 2009; 22 (5): 406-11. DOI:10.3415/VCOT-08-060051

2. Abd El Raouf, M., N.H.M. Mekkawy, and A.M. AbdEl-Aal. 'Femur fractures and treatment options in 20 dogs admitted to our clinic from January 2013 to December 2015. Iraqi Journal of Veterinary Sciences. 2017; 31: 117-22. DOI: 10.33899/ijvs.2017.145608

3. Piermattei DL, Flo GL, DeCamp CE. Brinker, Piermattei, and Flo's handbook of small animal orthopedics and fracture repair. $4^{\text {th }}$ ed. St. Louis: Saunders Company; 2006. 818 p. DOI: 10.1016/B978-0-72169214-2.X5001-1

4. Kolata RJ. Trauma in dogs and cats: An overview. Vet Clin North Am Small Anim Pract. 1980; 10 (3): 515-22. DOI: 10.1016/s01955616(80)50051-3

5. Ben Ali L. M. Incidence, occurrence, classification and outcome of small animal fractures: A retrospective study (2005-2010). Intern J Anim Vet Sci. 2013. 7 (3): 191- 96. DOI.10.5281/zenodo.1082359.

6. Conzemius, M., and S. Swainson. Fracture fixation with screws and bone plates, Vet Clin North Am Small Anim Pract. 1999; 29: 1117-33. DOI:10.1016/s0195-5616(99)50105-8.

7. Senn NA, Gadallah SM, Zabady MK. Studies on some bone disorders in cats: incidence, radiological assessment and surgical management. J Egypt Vet Med Assoc. 2004. 64; 113-37. DOI: 483ef8a1d36f65db376dd5a13be3083671c9

8. DeCamp CE, Johnston SA, Déjardin LcM, Schaefer SL. Brinker, Piermattei, and Flo's. Handbook of small animal orthopedics and fracture repair. $5^{\text {th }}$ ed. St. Louis: Elsevier; 2016. 868 p. DOI: https://doi.org/10.1016/C2009-0-64185-4

9. Kagadis GC, Langer SG. Informatics in medical imaging. Boca Raton: CRC Press; 2012. 349 p. DOI: 0094-2405/2012/39(3)/1680/2/\$30.00

10. Olisemeke, B., Y. F. Chen, K. Hemming, and A. Girling. 'The effectiveness of service delivery initiatives at improving patients' waiting times in clinical radiology departments: a systematic review', J Digit Imaging. 2014; 27: 751-78. DOI: 10.1007/s10278-014-9706-Z

11. Johnson AL, DeCamp CE. External skeletal fixation: Linear fixators. Vet Clin North Am Small Anim Pract. 1999; 29 (5): 1135-52. DOI: 10.1016/S0195-5616(99)50106-X

12. Lewis DD, Cross AR, Carmichael S, Anderson MA. Recent advances in external skeletal fixation. J Small Anim Pract. 2001; 42 (3): 103-12. DOI: 10.1111/j.1748-5827.2001.tb02006.x 
13. Harari J. Treatments for feline long bone fractures. Vet Clin North Am Small Anim Pract. 2002; 32 (4): 927-47. DOI: 10.1016/s01955616(02)00025-6

14. Sawyer, D. The Practice of Veterinary Anesthesia. 1st Ed. New York: Teton New Media; 2008. 14- 35 p. DOI: 10.1201/b16183

15. Carioto, L. Miller's Anatomy of the Dog. 4th ed. Elsevier, St Louis; 2013. 381 p. ISBN: 9780323266239

16. Taichman RS. Blood and bone: Two tissues whose fates are intertwined to create the hematopoietic stem-cell niche. Blood. 2005;105 (7): 26319. DOI:10.1182/blood-2004-06-2480

17. Singaram, S., and M. Naidoo. The physical, psychological and social impact of long bone fractures on adults: A review. Afr J Prim Health Care Fam Med. 2019; 11: 1-9. DOI: 10.4102/phcfm.v11i1.1908

18. Fossum TW. Small animal surgery textbook. New York: Elsevier Health Sciences; 2007. 1033-1093. ISBN: 9780323443425

19. White RA. Bilateral patellar fracture in a dog. J Small Anim Pract. 1977;18 (4): 261-5. DOI:10.1111/j.1748-5827.1977.tb05880

20. Walker T, Modayil P, Cascarini L, Collyer J. Dog bite- fracture of the mandible in a 9 month old infant: a case report. Cases J. 2009; 2 (1): 44. DOI: $10.1186 / 1757-1626-2-44$

21. Maley JR, Dvorak LD, Bahr A. Diagnosis and management of a fracture of the lateral trochlear ridge of the talus in a dog. Vet Comp Orthop Traumatol. 2010; 23 (4): 284-8. DOI: 10.3415/VCOT-09-070077

22. Riggs GG, Arzi B. Diagnostic imaging in veterinary dental practice. Root fracture of a maxillary canine tooth in a dog. J Am Vet Med Assoc. 2014; 245 (5): 497-9. DOI:10.2460/javma.236.1.41

23. Van der Stelt, P. F. Better imaging: the advantages of digital radiography. J Am Dent Assoc. 2008; 139: 7-13. DOI: 10.14219/jada.archive.2008.0357

24. Hattersley RD, Trevail T, Comerford EJ. Computed tomographic findings and treatment of an unusual fracture of the proximal ulna in a mature dog. Vet Comp Orthop Traumatol. 2011; 24 (2): 161- 4. DOI: 10.3415/VCOT-10-05-0068

25. Takaki T, Fujibuchi T, Murakami S, Aoki T, Ohki M. The clinical significance of modifying X-ray tube current-time product based on prior image deviation index for digital radiography. Phys Med. 2019; 63: 35-40. DOI: 10.1016/j.ejmp. 2019.05.011

26. Carter C, Veale B. Digital radiography and PACS E-Book. $2^{\text {nd }}$ ed. New York: Elsevier Health Sciences. 2018; 205-241 p. ISBN 9780323547598

27. Seeram E. Digital Radiography: Physical Principles and Quality Control: Springer Singapore, $2^{\text {nd }}$ edition. 2019; 87- 93 p. DOI: 10.1007/978-981-13-3244-9

28. Hunt CA, Henry WB, Jr. Trans-articular pinning for repair of hip dislocation in the dog: a retrospective study of 40 cases. J Am Vet Med Assoc. 1985; 187 (8): 828-33. ISSN 0003-1488

29. McClure S, Acvs D, Watkins J, Acvs D, Ashman R. In vivo evaluation of intramedullary interlocking nail fixation of transverse femoral osteotomies in foals. Vet Surg. 1998; 27 (1): 29-36. DOI:10.1111/j.1532-950x.1998.tb00094.x

30. Abd El Raouf, Mustafa, S.A. Ezzeldein, and E.F.M. Eisa. Bone fractures in dogs: A retrospective study of 129 dogs. Iraqi Journal of Veterinary Sciences. 2019; 33: 401-5. DOI:10.33899/ijvs.2019.163086

31. Manley P. Principles of fracture fixation in growing animals. Semin Vet Med Surg. 1992; 7 (1): 36-43. DOI: 10.12968/bjon.1993.2.9.483

32. Tianye L, Peng Y, Jingli X, QiuShi W, GuangQuan Z, Wei H. Finite element analysis of different internal fixation methods for the treatment of Pauwels type III femoral neck fracture. Biomed Pharmacother. 2019; 112: 108658. DOI: $10.1016 /$ j.biopha.2019.108658

33. Sukegawa S, Kanno T, Masui M, Sukegawa-Takahashi Y, Kishimoto $\mathrm{T}$, Sato A. Which fixation methods are better between threedimensional anatomical plate and two miniplates for the mandibular subcondylar fracture open treatment. J Craniomaxillofac Surg. 2019; 47 (5): 771-7. DOI: 10.1016/j.jcms.2019.01.033

34. Andrianov, V., G. Tralman, R. Hõim, T. Haviko, A. Lenzner, M. Pääsuke, A. Arend, and M. Aunapuu. Rod-through-plate fixation of canine diaphyseal fractures. Vet Comp Orthop Traumatol. 2007; 20: 308-11. DOI: 10.1160/VCOT-06-12-0095

35. McLaughlin, Ron. Internal Fixation: Intramedullary Pins, Cerclage Wires, and Interlocking Nails. Veterinary Clinics of North America: Small Animal Practice. 1999; 29: 1097-116. DOI: 10.1016/S01955616(99)50104-6

36. Hutchinson PH, Bae DS, Waters PM. Intramedullary nailing versus percutaneous pin fixation of pediatric proximal humerus fractures: a comparison of complications and early radiographic results. J Pediatr Orthop. 2011; 31 (6): 617-22. DOI: 10.1097/BPO.0b013e3182210903

37. Zhu L, Ho H, Lu W, Leung F, Chow SP. A cadaveric model for biomechanical study of fixation methods for AO type $\mathrm{C} 2$ fractures of distal radius: design and testing with dorsal plating fixation. Hand Surg. 2002; 7 (2): 279-83. DOI: 10.1142/S0218810402001163

38. Stein H, Volpin G, Horesh Z, Hoerer D. Cast or external fixation for fracture of the distal radius. A prospective study of 126 cases. Acta Orthop Scand. 1990; 61 (5): 453-6. DOI:10.3109/17453679008993561

39. Slatter DH. Textbook of small animal surgery: $3^{\text {rd }}$ ed. Vol 1. New York: Saunders; 2003.1785-95. ISBN: 0721686079, 9780721686073

40. Claes, L. Mechanobiologie der Frakturheilung Teil 2. Unfallchirurg. 2017; 120: 23-31. DOI:10.1007/s00113-016-0281-2

41. Mattei, L., F. Di Puccio, and S. Marchetti. In vivo impact testing on a lengthened femur with external fixation: a future option for the noninvasive monitoring of fracture healing. J R Soc Interface. 2018; 15 (142): 20180068. DOI: 10.1098/rsif.2018.0068

42. Beale B. Orthopedic clinical techniques femur fracture repair. Clin Tech Small Anim Pract. 2004; 19 (3): 134-50. DOI: 10.1053/j.ctsap.2004.09.006

43. Rodriguez-Collazo ER, Urso ML. Combined use of the Ilizarov method, concentrated bone marrow aspirate (cBMA), and platelet-rich plasma (PRP) to expedite healing of bimalleolar fractures. Strategies Trauma Limb Reconstr. 2015; 10 (3): 161-6. DOI: 10.1007/s11751015-0239-x

44. Lim EJ, Kim JT, Kim CH, Kim JW, Chang JS, Yoon PW. Effect of preoperative bisphosphonate treatment on fracture healing after internal fixation treatment of intertrochanteric femoral fractures. Hip Pelvis. 2019; 31 (2): 75-81. DOI: 10.5371/hp.2019.31.2.75.

45. Thanoon, Moyaser, M.J. Eesa, and E.R. Abed. Effects of platelets rich fibrin and bone marrow on the healing of distal radial fracture in local dogs: Comparative study. Iraqi Journal of Veterinary Sciences. 2019; 33: 419-25. DOI: 10.33899/ijvs.2019.163169
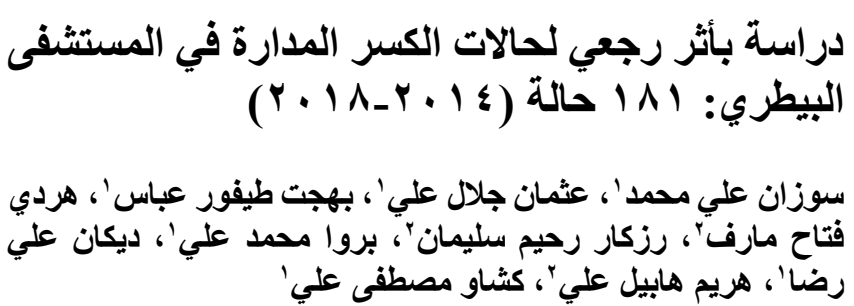

$$
\begin{aligned}
& \text { 'فرع الجراحة و التناسل، ‘فرع السريريات و الطب الباطني، كلية الطب }
\end{aligned}
$$

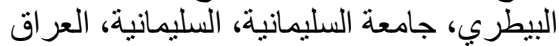

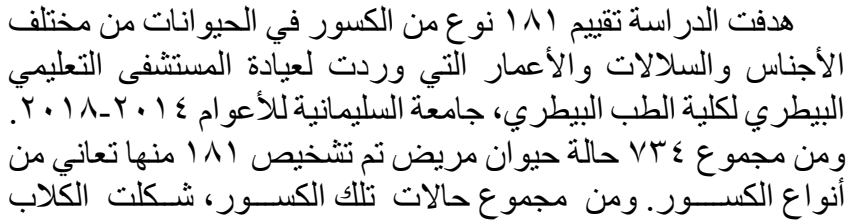


كانت 7 منها ميؤوس علاجها، و 0؛ منها تم علاج الكسور فيها بتثبيتها

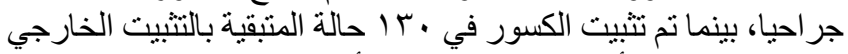

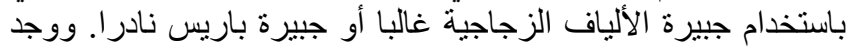

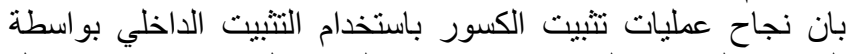

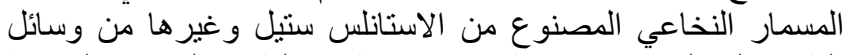

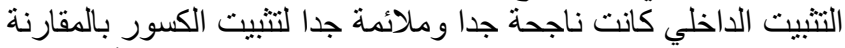

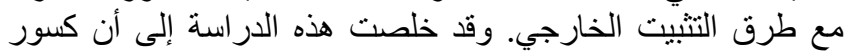
العظام في الحيو انات يجب الأخذ بها بنظر الاعتبار في مدينة السليمانية الإنية

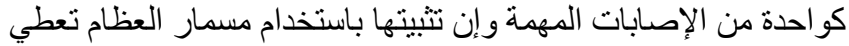
نتائج إيجابية في حالة العلاج.

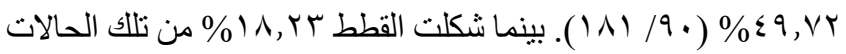

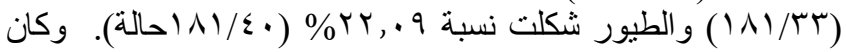

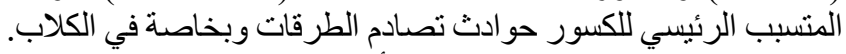

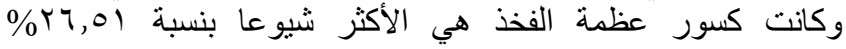

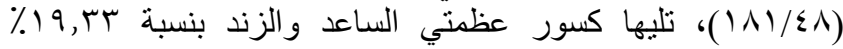

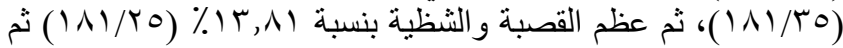

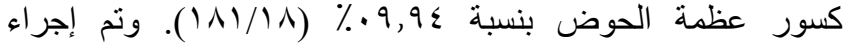

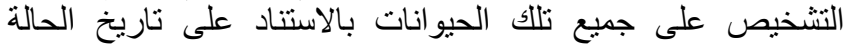
المرضية والفحص السريري ونم التشخيص لكل منها باستخدام جهاز

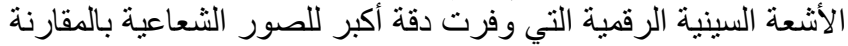

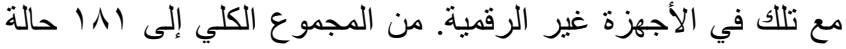

